\title{
Actors, resources, activities and commitments
}

\author{
Peter Lenney ${ }^{*}$, Geoff Easton ${ }^{1}$ \\ Lancaster University Management School, Lancaster University, Lancaster, LA1 4YX, United Kingdom
}

\section{A R T I C L E I N F O}

\section{Article history:}

Received 1 February 2008

Received in revised form 1 August 2008

Accepted 1 December 2008

Available online 12 June 2009

\section{Keywords:}

Commitments

Actors-resources-activities model

B2B relationships

Managerial work

Marketing managerial work

\begin{abstract}
A B S T R A C T
A new concept, commitments, is introduced and defined as "agreements between two or more social actors to carry out future actions" and its incorporation into, and articulation of, the actors-resources-activities model described. Commitments are distinguished from the concept of commitment as traditionally used in inter-organisational relationships. The latter is mainly an affective measure at the level of an individual concerning the general relationship between buying and selling organisations. By contrast commitments are agreements made between actors and range from the specific and everyday to the general and strategic. The theoretical background and nature of commitments are described and how commitments relate to and enrich each of the elements of the ARA model demonstrated. The application of the concept to B2B relationships at the level of individual, group, organisational and net actors is set out and implications of the use of the commitments concept for researchers and managers are suggested.
\end{abstract}

(c) 2009 Elsevier Inc. All rights reserved.

\section{Introduction}

In this paper we introduce the concept of commitments which is defined as; "agreements between two or more social actors to carry out future actions".

For example - "I will make sure that you are informed earlier next time".

The term commitments is used in the plural in this paper in order to indicate that it is a different use of the word commitment, from that which is deployed in B2B network relationship descriptions, where it is used alongside 'trust' to describe positive affective, attitudinal and behavioural aspects of relationships between actors which are likely to lead to the continuation of a relationship.

Commitment resides within actors, such that one actor may be fully committed to another while the other actor may not be at all committed. In contrast commitments essentially exist in the space between actors.

We show how this concept can be used to enrich and articulate the actors, resources and activities (ARA) model (Hakansson \& Johanson, 1992). The commitments concept introduces the notion of purposiveness into the model and in doing so provides a clearer view of how and why actors, resources and activities are linked and helps to explain interaction and network outcomes.

The ARA model represented a major step forward in terms of conceptualising B2B relationships and networks. It is not simply that it

\footnotetext{
* Corresponding author. Tel.: +44 1524593398.

E-mail addresses: p.lenney@lancaster.ac.uk (P. Lenney), g.easton@lancaster.ac.uk (G. Easton).

1 Tel.: +44 1524593917
}

identified a trio of concepts. It also suggested mechanisms by which the entities relate to one another. It proposed that the three entities, actors, resources and activities captured the key aspects of relationships, both between firms, as in B2B relationships, but also within firms at all levels down to the relationships among individuals.

Actors act, that is to say they carry out activities usually in combination with other actors. Actors are goal directed and act in line with their goals which are transformed into more specific intentions. Through their activities actors transform and transfer resources in order to maintain and grow the more aggregated actor, for example the organisation, of which they are a part. Actors are essentially human and can be individuals or collectivities such as groups, departments, organisations, or nets of organisations. Resources can be tangible or intangible, stable or unstable, valuable or worthless depending on their configuration. Activities can be of any kind and can take place at any level from the individual to the organisational net. Actors have control over some resources, access to others and work with other actors to create combine, develop, exchange or destroy resources.

The original model was further developed by the introduction of the concept of substance layers which binds together the three original entities into actor bonds, resource ties and activity links. Activity links provide the backbone of any organisation or inter-organisational relationships. They can be linked in any number of different ways though there usually exist pathways through these networks which comprise routines that allow for efficient operation. Resource ties connect various resource elements and can be entirely material as in the case of a production line consisting of a series of machines or entirely virtual as in the case of the combinations of human knowledge and skills that result in the creation of a new product design. These ties also represent another type of higher level resource as indicated in the 
previous examples. Actor bonds connect actors and so are primarily social in nature and involve perceptions, social cognitions, identity and affect. Bonds are created, nurtured and sometimes destroyed through interaction with other actors of various levels of aggregation.

The original 1992 chapter has been cited at least 260 times according to Google Scholar and the 1995 book has almost a 1000 citations. However a literature search suggests that rather few studies explicitly use either of the models to provide explanations of events. Rather they are used as frameworks to organise data and to tell stories. This is hardly surprising given the general nature of the model.

The elements of most theories and many models are necessarily abstract and parsimonious. They have to be to allow for the elements to be related to one another logically in order to explain events; that is to say to offer some insights into the phenomenon of interest. But to begin to offer explanations the elements of the model have to be operationalised. In the case of the ARA model for example it has to be made clear when analysing data who are the actors, what are their activities and with which resources they interact. In other words there has to be a bridge between the theoretical and the empirical. It may be that the generality of the ARA models is simply too great for potential users.

Another possibility is that additional concepts be included in the model. For example Welch and Wilkinson have proposed that actors' cognitions, expressed more specifically as their ideas, should be added (Welch \& Wilkinson, 2002). This would restrict the "degrees of freedom" that the model can have and so make it easier to fit to the data as well as offering the chance to enrich it. The process is rather like adding further independent variables to a multiple regression in order to explain more variation in the dependent variable. If some of the "variability" in the quantitative measures of phenomena are "explained", in terms of improved correlation, by such concepts, then the model becomes more powerful. On the other hand this makes such models more complicated to articulate and apply. Clearly there is a classic trade-off to be made between simplicity and richness. Other additions to the ARA model have also been suggested.

Our proposal is to extend the ARA model by incorporating into it the concept of commitments. By doing this the concept of actor purposiveness can now, to some degree, be addressed. As stated previously, actors are goal driven, goals lead to intentions and finally to actions, one very important category of which is to conduce commitments in others since individual actors can rarely achieve goals alone.

In general goals and intentions have not figured prominently in B2B research or theorising. They are mentioned, if at all, in rather vague ways often assuming some obvious direct link between actors' assumed goals and the actions that they are judged to have been taken as a result. However Håkansson et al. point out, in the context of comparing traditional marketing "theory" with the empirical results of the IMP group, "There is an interaction between goals and means" (Håkansson, Harrison, \& Waluszewski, 2007). In other words means do not necessarily follow goals; they may co-produce one another. Ford and McDowell take a similar non-traditional view with respect to strategic intent. "The intent may not be stated outright and it may not be conscious. It may, for instance, be expressed as part of the role of the job, expected and undertaken day in and day out. We believe that the degree to which the intent is recognised, expressed, communicated widely, and shared, is important for relationship strategy formation and realisation" (Ford \& McDowell, 1997). Given these complexities it is hardly surprising that the concepts of goals, objectives, intentions and, more generally, the purposiveness of actors have hardly been touched upon by researchers into B2B relationships.

Commitments are, by definition, the product of actors' intentions. Crucially they are empirically accessible since there is often material evidence for their existence. Also, asking actors what they have agreed to do, or what they have agreed with others that these others should do, provides far more grounded responses than asking them why they are doing something. Therefore commitments not only expose a crucial part of the mechanisms by which larger scale actors such as organisations and inter-organisations operate but, ultimately, also offer a means to access intentions and goals.

Commitments are a novel concept and their use in the B2B context provides an early example of how they might be used in other models and frameworks. It is clear therefore that this will be a conceptual paper, albeit dealing with a phenomenon with which every human actor is entirely familiar.

The paper is structured as follows. We begin by summarising the research on organisation and relationship commitment before defining commitments and explaining how they differ. The theoretical background and nature of commitments are then described. We then show how commitments relate to and enrich the elements of the ARA model and then extend the application to B2B relationships at the level of the individual, group, organisational and net actors. The paper ends with a conclusion and some implications of the use of the commitments concept for researchers and managers.

\section{Commitment}

It is important, first of all, to distinguish between commitment, which every B2B researcher is entirely familiar with, and commitments, of which they will not have heard. They are of course somewhat related but only marginally.

The term commitment has been used, and defined, in a number of different ways in a number of different fields. Perhaps the most prolific research has been in the Human Relations area focusing on the commitment of individuals to organisations. Such commitment has been measured in terms of individual's likelihood of leaving the organisation, a dependent variable that can be readily measured by means of staff turnover data. Since staff turnover is an important issue for most organisations, and the academic interest in commitment in this arena is readily understood. As a result it has tended to dominate the general field of commitment as an area of research.

While the concept of commitment in social life has a long tradition, interest in it in the organisational field was increased as a result of work by Allen and Meyer. They developed the three component model (TCM) of organisational commitment which is, in effect, an attempt to explain organisational behaviour in terms of "...a psychological state that links an individual to an organization (i.e. makes turnover less likely)" (Allen \& Meyer, 1990, p14). The three components are best described in terms of the adjectives affective, continuance and normative. "Employees with strong affective commitment remain because they want to, and those with strong continuance commitment because they feel they need to, and those with strong normative commitment because they ought to" (Allen \& Meyer, 1990, p3).

Solinger et al., reviewing existing definitions and descriptions of commitment, list the following as an alternative view as to what it comprises; a psychological state, a bond or link, an affective attachment, an orientation, a readiness to act or an unconflicted state of internal readiness. They conclude "There is widespread agreement that organizational commitment is an attitude" (Solinger, van Olffen, \& Roe, 2008, p72). The basic model has been tested many times but in practice the results have been disappointing (Randall, 1990).

The model has been further articulated in a number of ways. For example Bremmels (1995) argues that actors can have dual commitments, for example, in the organisational context, to both the organisation and to a trade union. This argument could also apply to individuals who are organisational boundary spanners, having commitments to both their own organisation and the customer or supplier. More generally individuals are always having to make trade-offs between competing priorities and ends, and their commitment is, as a result, likely to be fragmented. For example Becker and Billings (1993) identify the following foci; to a profession, supervisor, customer and customer commitment to supplier (Frow, 2007, p249). The last two of these are particularly relevant to buyer-supplier relationships. 
Dwyer, Schurr, and Oh (1987) were some of the first B2B researchers to refer to commitment in suggesting that it refers to “...an implicit or explicit pledge of relational continuity between exchange partners"(Dwyer et al., 1987, p221). However Morgan and Hunt provided the impetus for studying commitment in B2B relationships. They acknowledged their debt to other researchers in their definition of commitment. "Drawing on the conceptualizations of commitment in social exchange (Cook \& Emerson, 1978), marriage (Thompson \& Spanier, 1983), and organizations (Meyer \& Allen, 1984), we define relationship commitment as an exchange partner believing that an ongoing relationship with another is so important as to warrant maximum efforts at maintaining it; that is, the committed party believes the relationship is worth working on to ensure that it endures indefinitely" (Morgan \& Hunt, 1994, p23). This definition also applied to the commitment scales they developed. "Though no scale existed at the inception of our study for measuring commitment to an interorganisational relationship, eight items in the organizational commitment scales of Meyer and Allen (1984) and Mowday, Steers, and Porter (1979) reflected our definition. These eight were modified to reflect relationship, rather than organisational, commitment" (Morgan \& Hunt, 1994, p28). The scales were:

"The relationship that my firm has with my major supplier

...is something we are very committed to

...is something my firm intends to maintain indefinitely

...deserves our firm's maximum effort to maintain" (Morgan \& Hunt, 1994, p35).

The paper by Morgan and Hunt has over 3000 citations in Google Scholar and over 1000 in the Web of Science. It has been hugely influential in creating the trust-commitment theory field of study. It is not therefore surprising that many of the papers which quote Morgan and Hunt use commitment scales that are identical with, or have a great affinity to, their original scales.

However there have been some more recent developments. An analysis of a number of recent papers in Industrial Marketing Management suggests that there are 5 main groups of inter-organisational commitment scale items which include the following terms:

General statements of commitment -

Committed, proud to belong, loyal, an ally, sense of unity and recognition of attachment

Continuity -

Intend to continue, long term success and remain

Effort expended -

Make every effort, commit resources and investment

Affective -

Enjoy and like, friendly

Calculative -

Costly to terminate, makes sense moneywise and economically speaking.

Such terms are meant to apply to the totality of the relationship between buying and selling firms, hence their general nature. They are also clearly attitudinal and value laden in nature. In the next section we offer a complementary concept, that of commitments.

\section{Commitments}

\subsection{Definition}

We define commitments as agreements between two or more social actors to carry out future actions. The agreement will usually be asymmetric, in that one actor persuades another to agree to some action. Of course it is possible that something close to a balanced exchange can occur where both actors agree to act because of, and in exchange for, what the other actor has promised to deliver. Even in an asymmetric situation, the actor who conduces the commitment in another actor will usually have to at least acknowledge the fulfilment of the commitment. And the continuous and successful fulfilment of commitments by an actor would normally be expected to build social and political capital in the relationship with the commitment conducer.

More generally commitments are the seemingly simple undertakings through which someone agrees or accedes to a commitment. They may or may not be happy about the undertaking, and indeed will normally have a mixture of emotions attached to it and the processes involved, which could of course include indifference. Commitments are inter-subjective. Intentions could be described as internal commitments. However we prefer to keep the concepts separate since intentions involve largely psychological characteristics and commitments largely social ones. The social actors involved may be individuals, groups or departments in organisations, organisational dyads or nets.

\subsection{Genesis}

The perspectives developed in this paper emerged from a 30-month longitudinal field engagement (Lenney, 2006). The primary component of the fieldwork comprised a continuous 18-month participant selfobservation study by one of the authors during his engagement as an interim marketing director for an industrial goods company. Complementing this study, the activities and behaviour of several Business-to-Retail boundary spanning sales and marketing managers within a multi-billion global consumer goods company were studied also over a period of 18 months. The methods deployed in this more traditional study comprised participant observation, non-participant observation, and action research. The participant self-observation (Holbrook, 2002), the longitudinal nature of the non-participant observation, and the involvement in action research (Marples, 1967; Watson, 1994) provided a rich variety of data to test out the role of commitments in everyday inter-organisational life. In what follows some of the quotations are based upon recorded conversations in meetings but have had to be edited because of the organisational language and background that is necessary to comprehend the meaning of what was said. Some quotations are simply examples and these will be shown in italics.

\subsection{Theoretical foundations}

The genesis of our conception of commitments lies in the seminal work of Strauss, Schatzman, Ehrlich, Bucher, and Sabshin (1963) who studied staff behaviour at two psychiatric hospitals in an attempt to discover: "...how a measure of order is maintained in the face of inevitable changes" (Strauss et al., 1963, p148). Their central conclusion was simple: "The hospital can be visualised as a place where numerous agreements are continually being terminated or forgotten, but also continually being established, renewed, reviewed, revoked, revised..." (p164). However, most particularly, our notion of commitments builds on and exploits, the research on collaborative work carried out by Flores and Winograd and their co-workers (Flores \& Ludlow, 1980; Fikes, 1982; Winograd \& Flores, 1986; Winograd, 1987-88; Flores et al., 1988.), and its much more recent development and exploitation in the field of multi-agent/distributed artificial intelligence systems design (Jennings, 1993; Castelfranchi, 1998, 2000, 2001; Singh 1999). The commitments based perspective on cooperative work (Winograd, 1987-88) currently provides the basis for the software architecture supporting the development of virtualartificial societies (Sawyer, 2003), business process modelling systems (Dietz, 2006; Van Reijswould, Mulder, \& Dietz, 1999), collaborative task management software (Whittaker, 2005) and sophisticated electronic communication systems (Duchenault \& Watts, 2005). 
Winograd and Flores (1986, p150) describe organisations as "networks of commitments", with managerial work being the "articulation and activation" of this network. However, being systems developers, not organisation theorists they did not develop these ideas any further in terms of empirical social research.

The systems development driven treatment of commitments has really only had room for the simplest conception of commitments. However commitments are simple only in principle, and their crafting, conducing and fulfilling involve processes which are often both highly sophisticated and inextricably social. The commitments concept has not been exploited in organisational studies beyond Ford and Ford's (1995) inclusion of them in their treatment of "managerial conversations for change".

This neglect occurred despite the studies of managerial interactions undertaken by, for example, Boden (1994) and Samra-Fredricks (2000), and the central place of commissives (grammatical moods that indicate promises or threats) in the classical speech act theory of Austin (1962) and Searle (1979 Chapter 1). In her conversation analytic study of managerial work Boden concludes: "actors create and re-create their organizations.... Their talk...is the centre of their coordination" (Boden, 1994, p205). That coordination is the centre of their talk could equally well be argued. At the heart of their myriad formal and informal conversations and communications, are the processes that actually enable this process of coordination to be achieved and maintained; those of the crafting, conducing and fulfilment of commitments (Lenney, 2006 \& 2009).

\subsection{The nature of commitments}

Commitments are inherently future-laden, the reverse side of commitments being expectations. They are the vital coordinative managerial resource whose fulfilment enables coordination. They interleave purpose among and through actions. They form the basis for action although they are not always fulfilled as agreed. Commitment fulfilment is almost always temporally and spatially dislocated from its inception. In essence therefore all commitments are intrinsically goal commitments, but with differing extents and degrees of specification as to the 'how' of their fulfilment.

Commitments are, to some extent, depending on their specificity, fragile and intrinsically underdetermined. They tend to suffer from what might be termed 'looseness'. This is a fundamental property of commitments since it is rare that their constituent tasks can be comprehensively or rigorously specified in all their dimensions. Their inherent looseness, embedded futurity and perpetual re-interpretation ensure all commitments are somewhat precarious. Their perpetual monitoring, maintenance and modulation are part of the essence of managerial work.

Commitments can take many forms; they include, for example, commitments to:

$>$ Execute a physical act e.g. 'I will ring that supplier tomorrow?'

$>$ Execute a cognitive act e.g. 'OK, I'll think about it'

Prioritise/sequence e.g. 'Yes I will get her to sort this customer's order first'

$>$ Focus attention e.g. 'We'll watch the delivery statistics carefully' Exhibit certain behaviours e.g. 'Don't worry. I'll support you'

$>$ Allocate resources; for example:

- Financial e.g. 'Zeb OK!! I'll authorise the Zest ad' spend'

- Physical e.g. 'We will let them have that stock'

- Man-hours e.g.'I'll put Sandy on it full time'

$>$ Endeavour to achieve a projected outcome e.g. 'We'll do whatever it takes to get the product there'

$>$ Agree to a particular strategy "I will try to make sure that our KAM group improves relationships with all our customers not just some?".
A crucial feature of commitments is their level of specificity. Among the examples given above the first few are rather specific. It is clear what is required although less clear whether the commitment will be fulfilled as specified. However these kinds of commitments can be relatively easily monitored. The last two are, however, rather different. They are couched in much more general terms. There will usually be relationships between commitments of differing specificity. Less specific commitments like the two discussed above will require for their fulfilment any number of more specific commitments.

\section{The ARA model and commitments}

Each element of the ARA model is quite different from the other but their intimate relationships provide a rich picture of how both organisations and inter-organisations, that is to say relationships between organisations, actually operate. Commitments also differ from the other concepts. They can be regarded as a resource but one which reflects the goals of actors and not only involves but guides activities. The relationships between the original concepts and commitments will now be described in turn.

\subsection{Actor bonds and commitments}

Fig. 1 depicts 4 actors, two individual actors in organisation A (AI), the buying organisation, one individual in organisation $\mathrm{B}(\mathrm{BI})$, and one group actor (BG), the latter being in the selling organisation. The group in the selling organisation is, in this example, a Key Account Management team. All the actors are bonded one with another which implies a continuing social as well as economic relationship. In addition the group BG will also have internal social and formal bonds. At this point there also exist commitments both between and within actors, represented in the diagram by the boxes. The commitments are illustrated as being attached to one actor because commitments are made by one actor to another. For example the KAM group in the seller organisation might have a commitment which could be to provide the buyer $\mathrm{AI}$ in the buying organisation with a complete plan for the supply of a new component. Within BG each individual actor has a commitment to the other actors, and consequently, to AI to contribute to this planning process. Another AI in turn has a commitment to the KAM group to supply them with samples of the product in which the component will be incorporated. Finally BI, a senior manager, has a commitment to the KAM group to review their plan before it is sent to the buyer.

This set of commitments would represent only a very small part of the activities being carried out by any of the involved actors at the current time. Each actor is likely to have a portfolio of such commitments and each would have to decide on their commitment fulfilment priorities. Commitments made by aggregate actors such as departments, groups or KAM teams are more complex since the fulfilment of a group commitment requires agreement about the nature of the commitment, task allocations, group coordination and individual task completions. In well established groups, routines, whether formal or informal, will make this process easier. In one off
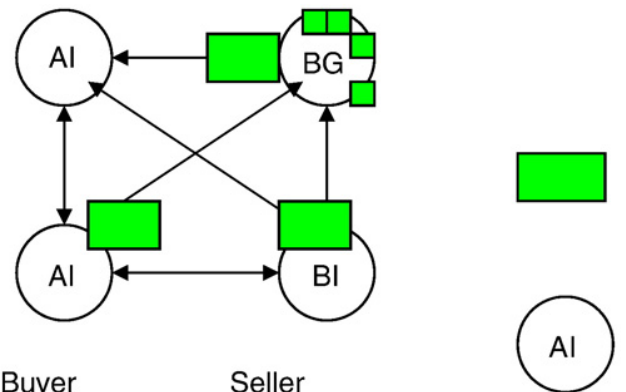

Commitment

Buyer Seller

Actor 
project situations it will be much more difficult and the nature of the individual commitment will be a matter for negotiation.

A crucial factor that will affect the nature of the commitment is the social capital that exists between the actors involved. In addition the number and history of past commitments that have been made and fulfilled, and the quality of such completions will also be important. It also seems likely that the affect entailed in the relationship will be a major influence on how commitments are created and fulfilled.

In the situation described above none of the commitments are entirely mutual or balanced. Mutual commitments imply that, for example, an actor agrees to a commitment but only in exchange for a commitment by the other party.

\subsection{Activity links and commitments}

The key activities involving commitments are their conducing and fulfilling. Conducing commitments is, like anything to do with commitments, an everyday activity, in and between organisations. However it has a particular significance because of the division of labour, the existence of hierarchy and structure and the concomitant requirement for coordinated action.

The process of conducing commitments is driven by the goals of the actor involved, and those goals exist at varying levels of specificity, importance and urgency. The first option for individual actors is to attain their own goals by creating internal commitments, which we would prefer to call intentions to distinguish them from inter-actor agreements ("I really need to arrange a meeting with the customer quality control department"). A particular form of intention is that which involves the acts of conducing commitments in other actors ("I will get Beverley to arrange a meeting with the customer quality control department"). The final form of intention is that which involves fulfilling commitments the actors themselves have made ("Yvonne will be getting back to me soon if I don't to arrange a meeting with the customer quality control department"). As a result actors will always be aware that they have a portfolio of intentions and commitments that they know that they will either intend to fulfil themselves or conduce in others. The evidence for the existence of intentions and commitments is available in the to do lists, task files, diary entries and post it notes which are to be found in all organisations.

The activities of conducing and fulfilling of commitments are clearly central to any organisation or inter-organisation. Conducing commitments as a process depends on the social and political relationships of the actors involved. There are many sources of power in organisations, and inter-organisations, of which formal power is only one. For example rational arguments are often suggested as the most important route to persuade others that they should agree to a particular course of action. On the other hand doing a favour for a friend works too, through the invocation of social power.

The strength of the commitment can usually be judged during this process. Phrases like "I'll try" and "If I have time" probably signal weak commitment. In addition the specificity of the commitment and its perception by both parties is crucial in terms of its fulfilment. This is particularly important in terms of the time scale agreed. "In the next few days" is very different from "By Friday at 10 at the latest". The precision with which the outcome is defined helps to determine how the fulfilment of a commitment is judged by the parties involved. In particular, if there are metrics involved, it becomes easier to judge whether a commitment has been met. "Ok I will write up the minutes of the meeting listing all the points of agreement and disagreement and present them to the customer for approval" is very different from "OK I will have a talk to the customer to see what he felt we got out of the meeting".

Commitments can be quite labile and often change character as attempts are made to fulfil them or they are overtaken by events. The former emphasises the point that commitments are, in effect, simply agreements to undertake to do something which may or may not be possible to achieve. Many organisational and inter-organisational activities are essentially routinised and so commitments can be expected to be fulfilled with little or no modulation. But others may require quite new activities to be carried out and so are likely to be less predictable in terms of their eventual outcomes. The latter reminds us that change is inevitable and that what was possible yesterday may not be possible today.

The lability of commitments is the major reason why commitments are not necessarily single cycle activities. If a commitment appears as though it cannot be fulfilled in whole or in part then it is often the case that the parties will be forced to try again or revise the nature of the commitment. Usually there will be reasonable grounds for doing so. However a tactic sometimes used in this context is to accept a commitment with a view to modulating it at some future date.

The foregoing description of the conducing and fulfilling of commitments makes it clear that commitments provide a mechanism by which activities are linked. This is true for both one off and routinised organisational and inter-organisational activities. In the latter case commitment cycles programme the basic commitments and the necessary activities which are, however, modulated on a regular basis within certain acceptable parameters.

\subsection{Resources ties and commitments}

Commitments if they are to be fulfilled require resources, as well as creating, modifying, using and destroying them. Since any actor is a resource, the simple act of making and accepting a commitment uses actor implicated resources. This process can sometimes be long and protracted and is the price paid for coordinating actor activities. It could be likened to friction within a machine.

Fulfilling commitments will also involve the use of resources and these can be many and varied. For example a KAM team creating a plan for the supply of a new component, as in the example above, will draw on human resources such as team actors' knowledge, expertise and creativity as well as relational resources outside the team, physical resources such as lap tops and virtual resources such as the internet.

What is also clear from this example is that commitments help determine both temporary and permanent resource ties. In this example, once the plan has been created, the resource ties employed in its completion are free to be used in other resource tie configurations. Most obviously the individuals involved, although no doubt multitasking throughout the project, now have time to devote to other activities involving other resources. However there are rather more permanent kinds of resources ties, the most obvious of which are those linking actors. Organisational and, less obviously, interorganisational structures and job descriptions prescribe the ties that exist between people, groups, departments and organisations. While these are neither entirely prescriptive nor totally determining, they do provide a framework within which actors have to operate. Put another way, there exist rather generalised commitments which commit actors to certain kinds of activities and deny them the ability to undertake others. For example the membership of the KAM team brings with it responsibilities, which are simply another form of relatively underspecified commitment.

Non-actor resource configurations such as office layouts, available e-technology and manufacturing plant arrangements are created and modified by and through commitmenting processes. However when they are in place they are generally less capable of modulation in their structures and are therefore more likely to frame the ways in which commitments can be made rather than the other way around.

It could be argued that commitments are simply another form of organisational or inter-organisational resource. They exist, although in a somewhat ephemeral form. They involve actors, activities and other resources. They can be drawn upon and used. However the key difference is that commitments are purposive. They provide a crucial link between the goals of actors and their actions. Without 
this link explaining the reasons why certain activities occurred is close to impossible.

\section{Buyer-seller relationships and commitments}

The role of commitments has so far been developed largely in respect of organisational rather than inter-organisational relationships since it is somewhat easier to describe the key concepts and their relationships at the organisational level. However given that the ARA framework is essentially designed to model B2B relationships and networks the role of commitments in the inter-organisational context is the main focus of the rest of the paper.

First we would argue that any market based organisations that are involved in even a single exchange, economic or otherwise, are or more accurately have been, involved in a buyer-seller relationship. The two organisations stand in some relationship to one another at the point in time at which they exchanged and even if there is no second exchange its residue may last and have effects for both of them. For example a simple piece of information passed from one organisation to another can have a major impact. However it has to be acknowledged that strong, long term and intense relationships are more important, both for the organisations concerned and for the study of networks and these are the exchange situations that we will be concentrating on in the remainder of the paper. The way that commitments are involved in such relationships, and their character, depends on the actors involved.

\subsection{Individual level commitments}

It is tempting to argue that most day to day inter-organisational interactions will take place at the level of the individual (Mainela \& Tahtinen, 2007). The creation of commitments can come from either buyer or seller employees and will typically be concerned with managing the planning and delivery of the existing product/service flow.

An individual level B2B discussion of any kind will normally involve the crafting and fulfilment of short term commitments. Commitments are entailed even in the case where there is no long term relationship for example involving sales query situations. In the simplest case individuals' craft commitments in other individuals in partner organisations, for example requests from a buyer to a salesperson for a price discount which is within the salesperson's authority to grant. The salesperson might then commit to a response in a few hours. Alternatively the salesperson could discuss the request and make a decision almost straight away in which case the commitment would be captured instantaneously ("Can you give me an assurance that the price won't change this year? Sure. Of course I can"). This exchange draws attention to the fact that the capturing and fulfilling of a commitment can take anything from a few seconds to many years.

However much inter-organisational activity will be regular and some will be routinised. In this case commitments will be crafted and fulfilled within an agreed set of more or less flexible parameters based upon past experience (an operations manager checking every Friday with a customer buyer regarding deliveries received that week). Such routines may, of course, be modulated and adapted over time. Routines themselves can also be either planned or emergent. A planned routine may require the actors carrying out the routine to commit themselves to both the nature of the activity and its routinisation (So you want this information every week in the future?). This will involve a degree of consultation and discussion between individuals in the two organisations before it can be agreed. Emergent routines will normally be incremental in nature and involve rather specific commitments and activities. However they are likely to be easier to modulate since they have been created by the individuals concerned and are presumably helpful to both. In either case the agreement to institutionalise a routine is itself a commitment.

\subsection{Group level commitments}

While much inter-organisational commitmenting occurs at the level of the individual it will usually occur within, and be strongly influenced by, groups of which the individuals are members and to which they are more or less strongly connected.

Fig. 2 illustrates probably the most common buyer-seller interaction situation with multiple commitments involved. In this example commitments are crafted by actors within the buying organisation (a purchasing director and an operations manager) in a boundary actor (a specialist buyer) to find out if a supplier can modify one of the components they are already buying. The buyer then creates a commitment in the parallel actor in the other organisation (a salesperson) which is to answer the sales query. The salesperson cannot fulfil the commitment but crafts commitments (in an engineering manager and a sales manager) to determine whether the supplier can meet the request.

Much inter-organisational activity will be of this type. The specialisation that is required in most organisations means that interaction with other organisations on even simple matters requires the involvement, albeit often briefly, of a relatively large number of people on both sides.

Again such connections may be emergent or planned. In the former case the groups will largely be informal and may not even consider themselves to be a part of an inter-organisational group. It could, for example, include members of sales, marketing, operations, production control, accounts and quality control in both organisations. In fact it could be argued that, in traditional network mode, all individual actors are in fact connected to all the other actors in any buyer-seller dyad. However many of the relationships will be regarded as second order in that some actors will have little or no contact with anyone in the partner organisation. Their relationships are mediated through actors who have direct contact with members of the partner organisations.

Also, in practice, there are likely to be clusters and groupings of individual actors within and between organisations which can be identified by the strength of the actor bonds between and among them. One measure of that strength would be the number and potency of commitments that have taken place within those bonds. It is also less likely, in emergent groups, that ties will correspond to the formal lines of communication in the organisations concerned.

Planned inter-organisational groupings could involve one off project teams created in order, for example, to help install a common EDI system or jointly develop new logistics procedures. However organisational structures such as Key Account Management systems are often used to provide a framework for coordinating activities between buying and selling organisations. In doing so they tend to formalise and rationalise commitments. In the case of the selling organisation they can specify, or at the very least provide a forum for deciding, what commitments can be made by whom to a particular customer and how and when those commitments are to be fulfilled. In the case of EDI and web based systems some kinds of commitments can be automatically specified, created and fulfilled.

Finally, in terms of group level interactions, there will almost always be a number of individual actors in each organisation who will

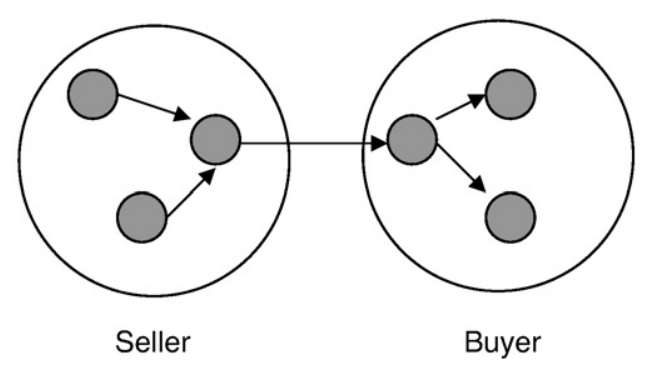

Fig. 2. Group level commitmenting and fulfilling. 
have regular independent contact with individual actors in the counterpart organisation.

The implication of this kind of inter-organisational net is that coordination of the activities in supplier-customer relationships becomes more difficult because the overall pattern of commitments entered into is not fully known by any of the actors. The problem becomes even more acute when these same actors also have to inhabit other nets involving portfolios of customers or suppliers.

Within the inter-organisational groups described above, another process will normally be observed; the emergence of higher level, less well specified commitments. These might include norms of performance and behaviour and even affect. For example acceptance that quality of components is much more important to a particular customer than delivery or price. Or a specific customer has to accept that their purchases are simply not large enough for them to expect high levels of service. In the first case the selling organisation makes the commitment and in the second the customer, albeit reluctantly.

What is crucial is that these are rather more general forms of commitment which frame everyday commitments and are affected by them. In other words they influence the day to day creation and fulfilment of commitments which in turn create and modify the norms.

\subsection{Organisational level commitments}

At the organisational level the commitments of one organisation to another will have a low level of specificity. For suppliers, such commitments will be concerned with how much resource, and of what sort, will be committed to this customer in the future. In B2B markets such decisions are essentially strategic, and are again, either emergent or planned. In the former case there is unlikely to be any formal evaluation of particular customers. Ad hoc decision making will take place which, if viewed over time, will indicate some underlying principles that could be called a customer evaluation and fulfilment strategy.

In contrast other suppliers adopt a formal system of customer analysis and rating where attempts are made to give weight to variables and parameters that can be used to evaluate current and possible future customer value.

There are a number of questions that could be asked which might help in making strategic customer commitment decisions.

Does this customer

- have the right characteristics of a customer in terms of their profitability, long term viability, positive relationship attitude and mutual learning opportunities?

- fit into our portfolio of customers in terms of synergies (positive and negative), risk and complementarities?

- help support/create our desired network position?

- fit in terms of how we are organised to handle our customer coordination and Key Account Management systems?

These kinds of questions help actors within the organisations concerned to frame their actions and the commitments to actions that they may have to make. While affect, and hence traditional notions of commitment, may influence decisions about what to do they do not usually determine them. Behaviour and affect are necessarily related in rather complex ways.

\subsection{Network level}

Commitments are clearly also involved in the creation of network level effects. A commitment made by one organisation B in a dyad to actor A may require, for its fulfilment, recourse to another actor up or down the supply chain or via an intermediary (a commitment by B to C). This may be for example the design and delivery of a subassembly to fit onto B's machine which A has ordered and will purchase. In other words two activity links need to be connected if the effect of the first is



Fig. 3. Connected activity links and commitment structure.

to be felt outside the original dyad A-B, i.e. within actor C. For a network effect to be present the activity links must go beyond A-B to $\mathrm{C}$ and perhaps beyond. This, in turn, means that commitments have to be crafted between actors B and C (see Fig. 3).

The flow through nodes model developed by Easton and Lundgren (1992) suggests that there are 5 possible modes of response that actor C can make when B attempts to craft a commitment to supply or buy a product or service for the first time. The first is simply reflection, when the actor $C$ cannot or will not accept a commitment. As a result there is no network effect. The second mode is adaptation, where the proposed commitment is changed through negotiation between the actors and subsequently accepted by actor $\mathrm{C}$ and a network effect is present; this is true for the rest of the cases. The third mode is absorption where actor $\mathrm{C}$ accepts the commitment, but then absorbs the results of doing so without involving any other actors. The network effect stops at this stage. Transmission is the fourth mode, and in this case the commitment is simply to transmit the incoming commitment through to another actor in the net and hence extend the network effect. The final mode is transformation, which involves actor $\mathrm{C}$ accepting the commitment and partly transmitting it and partly fulfilling it. In all cases, except reflection, network effects, of varying kinds, are realised and can be transmitted through the net.

These kinds of low level, highly specific commitments result in temporary network effects. Where there already exist higher level continuing commitments between say actors B and $C$ then the net becomes more clearly structured and permanent pathways through the net emerge.

\section{Conclusions and implications}

The novel concept of commitments has been used in this paper to extend and further articulate the well established actors-resourcesactivities model. Commitments have been shown to be intimately connected with each of the ARA concepts and their relationships. They are a component of actor bonds, a crucial type of resource that actors can draw upon and they are involved in a set of activities which determine which other activities take place. They are, to some extent, a missing link in the model since they introduce purposiveness as the driving force which helps to explain how particular events take place. Moreover we would argue that it has been demonstrated that the concept of commitments itself is novel, powerful and complex, and that some elements of that complexity have emerged from the discussion of commitments above. More generally commitments are an aspect of everyday social life and therefore have the potential to be useful in theorising about a wide range of social phenomena.

Commitments are crafted and fulfilled in order to achieve the particular objectives of the actors. Those objectives may be short term and highly specific but they accumulate to achieve higher level objectives and finally help explain the processes involved in, and the nature of B2B relationships. However commitments are not primarily created by top down processes through planning and control systems. Nor are they simply emergent from the day to day activities of the individual actors. They emerge from a continuous and dynamic interplay between these two processes. They are therefore particularly well suited for the study of organisations and more particularly their strategies and relationships with other organisations. 
There are a number of implications for researchers which spring from the recognition of commitments as a phenomenon to be studied. The first of these is that in studies which seek to understand why particular events occur, for example the ending of a relationship, discovering which actors made and fulfilled which commitments when, could provide valuable insights into the reasons for the events and the mechanisms involved. In particular the study of commitments can help to open the black boxes of actor intentions and goals. There is also work to be done on the micro processes of how commitments are crafted and fulfilled both within and between organisations, and how they combine, or are combined, to craft and fulfil broader objectives. Such research could derive inspiration from the research traditions in other social sciences involving the everyday practices of social actors and could draw upon, for example, the work on organisations as "communities of practice" (Brown \& Duguid, 1991).

There are also methodological implications. Studying everyday practices suggests that ethnographic approaches to commitments research should be used. However the nature of commitments is more or less readily understood by actors in organisations since they are involved in crafting and fulfilling them all the time and so can be revealed by relatively straightforward questioning. Current commitments are also often readily obtainable in the form of emails, Outlook task lists and calendars, and post it notes. However historical data may be more difficult to obtain except for the most important commitments.

Some of the most obvious interview questions for researchers could be "Who asked you to do that?", "Who did you ask to do that?", "What was it you asked them to do?", "What were you asked to do?", "Did you agree to do it?", "Did they agree to do it?", "Did you do it?", and "Did they do it?". The ability to focus on a particular commitment allows the interviewee to readily recall what happened but at the same time permits the researcher to explore the context of the commitment and then study the links between commitments to other actors. In this way an understanding of the events that are being researched is embedded in a framework which avoids the direct question "Why did that happen?. Instead starting with commitments grounds the research approach for the interviewees and automatically explores the links between actors. Even when actors work in groups it should be relatively clear which combinations are responsible for crafting and fulfilling which commitments. Some commitmenting processes will have been routinised (e.g. weekly progress meetings) and that should help in the data collection process.

In summary researching commitments offer not only a new concept with which to try to understand B2B relationships but also new and relatively uncomplicated ways of researching the research questions that arise.

There are also implications for managers. Most suggestions about what managers should do in response to implications sections of theoretical or empirical papers require them to undertake a massive amount of interpretation in order to be able to apply it to their own situation. We contend that the implications of recognising that much of their time is take up with commitmenting processes entail much less imagination. Managers will be only too aware that their day to day lives are concerned with undertaking, delegating and prioritising tasks. Other research suggests (Hales, 1999) that managers feel frustrated that they cannot logically and rationally plan and control as they would like. The commitments concept is one that is not only readily understandable, but also one that could help them in their immediate circumstances.

Understanding the role that commitments play in their own behaviour and the behaviour of others should be helpful in reducing this particular source of frustration. For example suggesting that managers should seek to understand why commitments remain unfilled might help them to uncover systemic issues or better ways of crafting the commitments in the first place. It might also be helpful to point out that commitment modulation is often necessary as a way of ensuring that the organisation is responding to changes in its environment and not simply the incompetence of others. It is important to recognise that managers' time is largely taken up in handling a portfolio of commitments and that their actions in fulfilling them as well as conducing them in others are, perhaps, the central task they must perform. Finally it is also essential that managers should comprehend the way that hierarchies of commitments are structured and operate. This would require them to question, but not reject, rational logical approaches to planning and organising but to recognise the role that commitments play in their operations, accept as normal their relative fragility and acknowledge the importance of taking that into account in their decision making.

Of course many of these suggestions are obvious and no doubt managers would be at least aware of the problems that they seek to alleviate. However the power of new concepts such as commitments lies in their ability to get people to look at the world in a new way, through a new lens.

\section{References}

Allen, N. J., \& Meyer, J. P. (1990). The measurement and antecedents of affective continuance and normative commitment to the organization. Journal of Occupational Psychology, 63(1), 1-18.

Austin, J. L. (1962). How to do things with words. Oxford: Clarendon.

Becker, T. E., \& Billings, R. S. (1993). Profiles of commitment: an empirical test. Journal of Organisational Behaviour, 14, 177-190.

Boden, D. (1994). The business of talk. Cambridge: Polity Press.

Bremmels, B. (1995). Dual commitment: - Unique construct or epiphenomenon. Labor Research, 16(4), 401-422.

Brown, J. S., \& Duguid, P. (1991). Organizational learning and communities-of-practice: Toward a unified view of working, learning, and innovation. Organization Science, 2(1), 40-57.

Castelfranchi, C. (1998). Modelling social action for AI agents. Artificial Intelligence, 103, 157-182.

Castelfranchi, C. (2000). Engineering social order. Lecture notes in computer science Berlin: Springer Verlag.

Castelfranchi, C. (2001). The theory of social functions: Challenges for computational social science and multi-agent learning. Journal of Cognitive Systems Research, 2 $5-38$.

Cook, K. S., \& Emerson, R. M. (1978). Power, equity and commitment in exchange networks. American Sociological Review, 43(5), 721-739.

Dietz, J. L. G. (2006). The deep structure of business processes. Communications of the ACM, 49(5), 60-64.

Duchenault, N., \& Watts, L. A. (2005). In search of coherence: a review of e-mail research. Human-Computer Interaction, 20(1), 11-48.

Dwyer, F. R., Schurr, P. H., \& Oh, S. (1987, April). Developing buyer-seller relationships. Journal of Marketing, 51, 11-27.

Easton, G., \& Lundgren, A. (1992). Changes in industrial networks as flow through nodes. In B. Axelsson \& G. Easton (Eds.), Industrial networks - a new view of reality London: Routledge.

Fikes, R. E. (1982). A commitment based framework for describing informal cooperative work. Cognitive Science, 6, 331-347.

Flores, F., \& Ludlow, J. (1980). Doing and speaking in the office. In G. Fick \& R. H. Springer (Eds.), Decision support systems New York: Pergamon Press.

Flores, F., et al. (1988). Computer systems and the design of organizational interaction. ACM Transactions on Office Information Systems, 6(2), 153-172.

Ford, J. D., \& Ford, L. W. (1995). The role of conversations in producing intentional change in organizations. Academy of Management Review, 20(3), 541-570.

Ford, D., \& McDowell, R. (1997). Intra-firm diversity and relationship strategy. In Gemunden Ritter \& Walter (Eds.), Relationships and networks in international markets (pp. 125-144). London: Pergamon.

Frow, P. (2007). The meaning of commitment in professional service relationships: A study of the meaning of commitment used by lawyers and their clients. Journal of Marketing Management, 23(3-4), 243-265.

Hakansson, H., \& Johanson, J. (1992). A model of industrial networks. In B. Axelson \& G Easton (Eds.), Industrial networks: a new view of reality London: Routledge.

Håkansson, H., Harrison, D., \& Waluszewski, A. (2007). Introduction: Rethinking marketing. In Håkansson Harrison \& Waluszewski (Eds.), Rethinking marketing London: John Wiley and Sons.

Hales, C. (1999). Why do managers do what they do? Reconciling evidence and theory in accounts of managerial work. British Journal of Management, 10(4), 335-350.

Holbrook, M. B. (2002, Fall). Having fun with qualitative methods or interpretative approaches in marketing and consumer research. ACR News, 5-8.

Jennings, N. R. (1993). Commitments and conventions: The foundation of coordination in multi-agent systems. Knowledge Engineering Review, 8(3), 223-250.

Lenney, P.W. (2006). In search of marketing management - a study of managing in marketing, Ph.D Doctoral Dissertation, Lancaster University, Lancaster U.K.

Lenney, P. W. (2009). The essence of marketing managerial work. VDM Velag Dr Muller Saarbrucken.

Marples, D. L. (1967, December). Studies of managers - A fresh start? Journal of Management Studies, 4(3), 282-299. 
Mainela, T., \& Tahtinen, J. (2007). Individual action constructing business relationships. Proceedings of the IMP conference, Manchester, UK.

Meyer, J. P., \& Allen, N. J. (1984). Testing the side-bet theory of organizational commitment: Some methodological considerations. Journal of Applied Psychology, 69(3), 372-378.

Morgan, R. M., \& Hunt, S. D. (1994, July). The commitment-trust theory of relationship marketing. Journal of Marketing, 58, 20-38.

Mowday, R. T., Steers, R. M., \& Porter, L. M. (1979). The measurement of organizational commitment. Journal of Vocational Behavior, 14(2), 224-247.

Randall, D. M. (1990). The consequences of organizational commitment: Methodological investigation. Journal of Organizational Behavior, 11(5), 361-378.

Samra-Fredricks, D. (2000). An analysis of the behavioural dynamics of corporate governance - A talk-based ethnography of a UK manufacturing 'board-in-action' Corporate Governance: An International Review, 8(4), 311-325.

Sawyer, R. K. (2003). Artificial societies. Sociological Methods and Research, 31(3), 325-363.

Searle, J. R. (1979). Expression and meaning - studies in the theory of speech acts. Cambridge: Cambridge University Press.

Singh, M. P. (1999). An ontology for commitments in multi-agent systems. Artificia Intelligence and Law, 7, 97-113.

Solinger, O. N., van Olffen, W., \& Roe, R. A. (2008). Beyond the three-component model of organizational commitment. Journal of Applied Psychology, 93(1), 70-83.

Strauss, A., Schatzman, L., Ehrlich, D., Bucher, R., \& Sabshin, M. (1963). The hospital and its negotiated order. In E Freidson (Ed.), The hospital in modern society (pp. 147-170). New York: Macmillan.

Thompson, L., \& Spanier, G. B. (1983). The end of marriage and acceptance of marital termination. Journal of Marriage and the Family, 45(1), 103-113.

Van Reijswould, V., Mulder, H. B. F., \& Dietz, J. L. G. (1999). Communicative action based business process and information systems modelling with DEMO. Information Systems Journal, 9, 117-138.
Watson, T. J. (1994). Managing, crafting and researching: Words, skill and imagination in shaping management research.British Journal of Management, 5, s77-s87 (2-Special).

Welch, C., \& Wilkinson, I. (2002). Idea logics and network theory in business marketing. Journal of Business-to-Business Marketing, 9(3), 27-48.

Winograd, T. (1987-88). A language-action perspective on the design of cooperative work. Human Computer Interaction, 3(1), 3-30.

Winograd, T., \& Flores, F. (1986). Understanding computers and cognition. Reading, Massachusetts: Addison Wesley.

Whittaker, S. (2005). Supporting collaborative task management in e-mail. HumanComputer Interaction, 20, 49-88 (1 and 2).

Peter Lenney is a Foundation for Management Education and ESRC Fellow in the Department of Marketing, Lancaster University Management School, U.K. and has a BSc Chemistry degree from Leeds University. Before becoming an academic on completion of his Ph.D. in 2006 his 20-year business career took him through various technical, marketing and commercial roles to become the Worldwide Business Director of International Paint Marine Coatings; a global $\$ 500$ million business supplying marine coating systems and services.

Geoff Easton is a Professor of Marketing, in the Department of Marketing, Lancaster University Management School in the United Kingdom. He has a BSc from Bristol University, a Dip. B.A, for Manchester Business School and was one of the first PhDs to graduate from London Business School. He has published in the Journal of Management Studies, The Journal of Business Research, Organization, International Journal of Research Marketing, Journal of World Business, Advances in Consumer Research and Advances in Complex Systems. He was the joint editor of, and contributor to, Industrial Networks: A New View of Reality, one of the keystone publications of the IMP group. 